Article

\title{
'Humorous Is the Only Truthful Way to Tell a Sad Story': Jonathan Safran Foer and Third Generation Holocaust Representation
}

\author{
Sarah Coakley \\ School of Humanities, University of Dundee, Dundee DD1 4HN, UK; s.r.coakley@dundee.ac.uk
}

Received: 30 August 2019; Accepted: 28 October 2019; Published: 30 October 2019

\begin{abstract}
Jonathan Safran Foer's representation of the Holocaust in his first novel, Everything is Illuminated, has been the subject of much controversy and critical debate. Several critics and Holocaust survivors have objected to the work for the lack of historical accuracy in its mythological narrative and the irreverence of its humour. However, such responses fail to take into account its specific form of generational representation: The Holocaust of Everything is Illuminated is always perceived through a third-generation lens, and its provocative elements instead highlight aspects of the experiences of the grandchildren of survivors. With this in mind, this paper examines Foer's approach to the Holocaust in Everything is Illuminated and Liev Schreiber's film adaptation (2005), making specific reference to the challenges faced by the third generation. Drawing upon theories of the transgenerational transmission of trauma and postmemory, it will explore the roles of creativity and humour in resilience, in addition to the reconstruction of a historical narrative under threat of erasure. Ultimately, by offsetting the tendencies to reduce the complexity of the Holocaust into unequivocal moralities (as exhibited in the film adaptation) with the idiosyncrasies of the third-generation experience, an alternative contextual perspective on the Holocaust is propounded, containing its own discrete set of ethical questions and concerns.
\end{abstract}

Keywords: trauma; Holocaust; third generation; humour; Jonathan Safran Foer

\section{Introduction}

As the seventy-fifth anniversary of the liberation of Auschwitz draws near, and the Holocaust transitions from living into historical memory, one thing is increasingly clear: we are still not quite sure how to address the topic historically, socially, and artistically. If the Holocaust is a wound on contemporary consciousness, it has certainly not yet healed. Nor would it be quite correct to consider the wounding as a specifically historical, finalised event, dislocated from the present. In fact, there is no group for whom the opposite is more true than those who Derek Parker Royal calls 'the psychological and spiritual inheritors of the Holocaust': the descendants of survivors, known as the second and third generations (Royal 2011, p. 4).

Recent research has, in fact, suggested that the use of the word 'inheritors' here is surprisingly literal, that the trauma of the Holocaust may be transmitted transgenerationally. This research spans multiple disciplines, including both those in the sciences (see, e.g., Gray et al. 2017; Lehrner and Yehuda 2018; Nugent et al. 2008; Ramo-Fernández et al. 2015; Samuels 2014; Wilker and Kolassa 2012; Yehuda et al. 2002, 2008; Yehuda and Bierer 2009), and social sciences (see, e.g., Chaitin 2002; Costa et al. 2018; Fromm 2012; Lev-Wiesel 2007; Scharf 2007; Scharf and Mayseless 2011). The dialogue between these different modes of research forms an image of a complicated interrelation of different modes of transmission, from epigenetic modifications transferred via gametes, to the social processes at work when a traumatised parent's behaviour impacts the child's life and world of meaning. The trauma 
story becomes central to family life, either through its ceaseless retelling or through its conspicuous absence when the traumatised individual is silent about their experiences. The result is what Marianne Hirsch calls 'postmemory', which she describes as 'the relationship of [subsequent generations] to powerful, often traumatic, experiences that preceded their births but that were nevertheless transmitted to them so deeply as to seem to constitute memories in their own right.' In this way, it can be described as a 'structure of inter- and trans-generational transmission of traumatic knowledge and experience. It is a consequence of traumatic recall but (unlike posttraumatic stress disorder) at a generational remove' (Hirsch 2008, pp. 103, 106). This emphasis on memory as the transmitter of traumatic knowledge is especially pertinent to studies in the transgenerational transmission of trauma, as it creates a clear distinction between the trauma of the survivor parent and the experiences of their descendants, whilst also highlighting the significance of these memories on subsequent generations' lives. This significance, however, is somewhat more complicated for the third generation. As more time elapses since the Holocaust, more and more survivors pass away. As a result, their testimony is lost, meaning that the third generation must rely on documentary and archival evidence to understand their family history, which, due to its destruction by the Nazis, is often sparse at best. In the words of Victoria Aarons and Alan L. Berger, drawing upon those of second generation survivor Melvin Jules Bukiet, "[i]f the "beginning" for the second generation was Auschwitz, the chronic and uncontainable awareness of the atrocities of the Holocaust, then the point of departure for the third generation is loss' (Aarons and Berger 2017, p. 32). The third generation, therefore, might not have sufficient access to the trauma story to understand their familial identity.

The second, and especially third, generation experience can consequently be described as a mediation between past and present; a confrontation with a past that is not their own but is nonetheless inescapable. More than this, it is a past that is, to an extent, fundamentally unknowable. As a consequence, many second and third generation survivors have turned to literature in an attempt to understand and work through their experiences and their complicated relationship to the Holocaust. Popular culture has proved an important domain for such inquiries, acting, as Christine Muller puts it, as 'our most widely encountered and commonly accessible forms of meaning-making' (Muller 2017, p. 2). Popular literature, then, not only constitutes an accessible and relatable space in which the narratives of the third generation can be created and disseminated, but also the opportunity to experiment with different aesthetic conventions (such as the postmodern) and to concretely make use of current cultural forms, including the creative aspects of humour that are so often absent from critical theory. Fundamentally, it reclaims their experiences out of clinical or academic contexts and into a more familiar world.

This is certainly the case for one such third generation survivor, Jonathan Safran Foer, whose popular novel Everything is Illuminated (2002) and Liev Schreiber's 2005 film adaptation will be considered in this article. Loosely based on a real journey Foer took to Ukraine in order to uncover his family's history, the narrative follows a young writer named Jonathan Safran Foer and his Ukrainian translator Alex as they search for the woman Jonathan believes helped his grandfather escape from the Nazis, and the remains of his shtetl, Trachimbrod. Ultimately, however, Jonathan finds nothing. Alex, by contrast, learns of his own grandfather's involvement in the Holocaust. The story is also, unexpectedly given the subject matter, incredibly funny, from the carnivalesque history of Trachimbrod to the ethnic comedy present in the contemporary narrative. As a result, both novel and film have received mixed reviews; amidst a great deal of excitement surrounding Foer generally, reviewers and survivors such as Henryk Grynberg have taken issue with the liberties the narrative has taken with regards to historical fact and its humorous tone (e.g., Franklin 2010, p. 240; Katchanovski 2004; Reisz 2002). In the words of Matthew J. Reisz, there is 'something oddly perverse' about the fact that the atrocities of the Holocaust are broached in a narrative that is so comedic (Reisz 2002, n. p.). It appears that in one fell swoop, Foer has broken all the rules of Holocaust convention. Yet, as this article will argue, these representational decisions (especially its humour) are a result of, and express, the third generation experience and responses to such an overwhelmingly traumatic event. In other 
words, these decisions are broached using contemporary aesthetics towards distinct ethical imperatives, arising specifically from the third generation's particular proximity to the Holocaust. In order to better understand the significance of such choices, however, it is important to first delve into the subject of Holocaust representation more generally.

\section{Holocaust Representation and Humour}

'To write poetry after Auschwitz is barbaric', or so states Theodor Adorno's famous dictum (Adorno 1981, p. 34). Yet, the Holocaust has become and remains a focal point of manifold literary, artistic, and popular works, provoking heated debates on subjects ranging from the possibility and ethics of representing the horror of the camps to the question of who has the authority to do so. It is perhaps of little surprise that this debate-as signified even in Adorno's dictum, which he even revised repeatedly as part of the ongoing discussion about representation-becomes especially contentious with regards to imaginative portrayals of the Holocaust. The conflict, which aims to prevent the truth of the Holocaust being forgotten, is broadly characterised by two competing perspectives. The first, espoused predominantly by figures such as Elie Wiesel, Claude Lanzmann, and Jean-François Lyotard, contends that the Holocaust fundamentally cannot be understood by those who were not directly affected, and as a result deems attempts at imaginative presentation unethical and favours documentary, factual, or testimonial evidence only (Lanzmann 1995; Lyotard 1997; Wiesel 1989). On the other hand, critics such as Berel Lang and Ruth Franklin highlight the threat that purely documentary forms of representation may reduce the trauma of the Holocaust to a dispassionate and detached series of facts that, in an ambition not to comprehend the incomprehensible, negates the emotional (and indeed human) character that is so fundamental to appreciating those very horrors that are deemed impenetrable (Franklin 2010; Lang 2000). In essence, we are left with a paradox: in the words of Franklin, 'confronting the Holocaust is impossible, yet the Holocaust requires us to confront it' (Franklin 2010, p. 6). It seems imperative, therefore, that these opposing viewpoints be reconciled in order that the truth of the past not be lost amidst debate.

The apparent compromise has been a strict—though not uncontentious-set of implicit representational guidelines through which the topic of the Holocaust might be broached. Drawing upon the work of Terrence Des Pres, Steve Lipman summarises these as 'insistence on the tragedy's uniqueness, minimal deviation from the historical facts, and a humorless presentation' (Lipman 1991, p. 7). Yet, these guidelines have been breached from the first imaginative works on the Holocaust, dating back as early as 1946 (see Franklin 2010). Perhaps the most notorious case with regard to historical fact, for example, is Fragments: Memories of a Wartime Childhood, a critically acclaimed 'memoir' written by Binjamin Wilkomirski (real name Bruno Dössekker) which turned out to be entirely fabricated. The revelation sparked global outrage, calling into question its value as a literary work. The emphasis on the uniqueness of the Holocaust (a subject which is, in fact, still consistently under debate) also appears to be frequently undermined by novelistic aims generally, in that they encourage intersubjective identification and employ points of relatability to this end. In the words of Franklin, 'literature, whatever its specific details, ultimately makes a case for universality. Art makes comparisons; it encourages empathy; it awakens the imagination. In short, it emphasizes the fundamental sameness of the human condition.' (Franklin 2010, p. 242). Often, this entails identification with different groups and histories, alongside wider contextualisation.

The third demand (humourless presentation), however, is arguably the most controversial. While the use of humour in Holocaust representation is widely considered to be disrespectful, even reprehensible (of course, in essence, there is nothing funny about the Holocaust), such responses tend to take a rather narrow view of the functions of humour, and indeed its relation to Jewish culture. Sigmund Freud, in his works on humour, suggested humour as an important mechanism by which suffering as a response to a stimulus can be prevented, instead producing pleasure (Freud 1960, Freud 1961). It is for this reason, he argues (supported later by critics and figures such as A. Roy Eckardt and Sarah Blacher Cohen), that it comprises an integral component in Jewish culture, allowing them to cope with 
the oppression and persecution inflicted upon the group throughout history (Freud 1960; Eckardt 1992; Cohen 1987). The use of humour in resilience, especially in the face of trauma, has furthermore been substantiated in recent research (e.g., Agaibi and Wilson 2005; Ostrower 2015; Sliter et al. 2014). For example, in their survey of 179 firefighters, Michael Sliter, Aron Kale and Zhenyu Yuan find that having a good sense of humour lowered incidence of both PTSD and burnout (Sliter et al. 2014). Therefore, in the words of Lipman, '[w]it produced on the precipice of hell [is] not frivolity, but psychological necessity' (Lipman 1991, p. 8).

Moreover, because, as Simon Critchley observes, humour relies on an incongruity between our knowledge of the subject and its presentation (Critchley 2002), it can also stimulate critical analysis of the subject by drawing attention to it. In this sense, rather than detracting from the gravity of the subject, humour can be used to highlight its seriousness. Consider, for example, Roberto Benigni's tendentious 1998 film Life is Beautiful (Benigni 1998). Several reviews have taken issue with Benigni's refusal to graphically portray the atrocities of the camps, and for the slapstick and lighthearted humour embodied in protagonist Guido, which they argue dilutes the terror. However, as Sylvia Levine Ginsparg notes, 'if we continue to show only the horror of the Shoah, we run the risk of it becoming banal' (Ginsparg 2003, p. 712). In addition, it is the incongruity between the barbarity that exists as a subtext within the film alongside the viewer's own cognizance of the cruelties of the camps-as Remi Lanzoni argues, 'only the most unacquainted spectator will not sense their existence' (Lanzoni 2000, p. 129)—-that makes it so disquieting. The juxtaposition, perhaps to a greater extent than a more explicit portrayal, stimulates a critical appraisal of the relationship between what is repressed (the realities of the Holocaust) and how it is approached.

Finally, as Critchley observes, in drawing attention to the relationship between the subject matter and its presentation, humour can be used as a tool towards positive social change. Because it destabilises and defamiliarizes our prior conceptions of social reality, it opens these frameworks to challenge, such as the way in which radical feminist humour challenges patriarchal norms (Critchley 2002). Similarly, Cohen argues that the predominance of humour in Jewish culture, especially in the face of antisemitism and historical oppression, is a method by which Jewish people refuse to ennoble suffering and death (Cohen 1987). It seems reasonable to suggest, then, that to dogmatically exclude humour from representations of the Holocaust potentiates generating a spectacle of suffering; the reduction of those persecuted (and the Jewish people more generally) into passive victimhood and the murdered into martyrs. In other words, such a move runs the risk of presenting the peoples concerned primarily as symbols rather than as individuals, and the privileging of suffering over resilience.

Humour, then, also antithetically connects to one final ingrained aspect of Holocaust discourse and representation: morality. Where other elements of Holocaust representation have proved very factious, the general consensus holds that the Holocaust possesses a distinct moral character, and one which must be acknowledged clearly (e.g., Braun 1994; Franklin 2010; Lang 2000). It is important that the suffering of the victims is not trivialised, and neither must the perpetrators of such suffering be excused, lest the crimes of the Holocaust be made banal or forgotten. In essence, the traditional view maintains that a strict moral dichotomy must be maintained; it is no coincidence that the moral argument is upheld strongly by advocates of the Holocaust's unrepresentability. Yet, just as with the previous guidelines, the strict causal relationship between drawing an unambiguous perpetrator/victim binary and the appropriate honouring of the Holocaust can — and has been — the subject of scrutiny. Ironically, the ethicality of such a prescription is especially called into question.

Given the relationship that the second and third generations bear to the Holocaust (as outlined in the introduction), then, it is probably unsurprising that the aforementioned guidelines for representation have been especially challenged in their approaches to the events of the twentieth century. In an analysis of the evolution of humorous Holocaust representation in Israeli television skits, Eyal Zandberg summarises this move succinctly as follows:

During the first generation of Holocaust survivors, the discourse was constructed as subordinate to the process of "nation-building," and was thus shaped mainly by the Establishment. The 
discourse of the second generation was intense and loud and was very conspicuous in Israeli popular culture. The third generation looked at Holocaust memory differently, expressing a special awareness of the socially constructed nature of the process of shaping collective memory and of their own role in shaping it; this change in perception allowed humor to be used to explore new ways of representation and to criticize traditional ones. Hence, while the second generation broke the silence of the first generation and put Holocaust memory in the forefront of public discourse, the third generation probed the limits of representation by using humor to challenge traditional commemoration. (Zandberg 2015, p. 118)

In this sense, by probing these limits, contemporary (and especially second and third generation) representation of the Holocaust is concerned not only with what is represented, but also representation itself. This is certainly true of Jonathan Safran Foer's Everything is Illuminated, as I hope to illustrate over the following pages.

\section{Everything Is Illuminated}

In many ways, Everything is Illuminated exemplifies an ambivalent attitude towards the ethics of Holocaust representation, and in fact explicitly brings the question to the fore. Foer's novel assumes an epistolary structure, comprising of chapters of the novels both the characters Jonathan and Alex write in response to their experiences searching for Trachimbrod. These chapters are interspersed with letters from Alex, who comments on Jonathan's writing, and refers to comments Jonathan appears to have made on his own. During these exchanges, a number of concerns are raised and interrogated, including the presence and types of humour used and factual accuracy. Indeed, the humorous tone of Everything is Illuminated is presented as the product of Jonathan's urging that 'humorous is the only truthful way to tell a sad story', a philosophy that recalls both the incongruous and resilience-bolstering aspects of humour. It is a representational guideline that the first part of Alex's narrative also evidently adheres to, before he ultimately distances himself from it in favour of a more serious and emotional perspective (Foer 2003, p. 53). Similarly, as they narrate the historical events of the Holocaust, the two men diverge completely in their approaches: whilst Jonathan's narrative ultimately disintegrates into pages of ellipses as Nazi bombs fall on Trachimbrod (the failure of language suggesting the actual Holocaust's unrepresentability), Alex's is characterised by an overabundance of language, as words and phrases bleed together in one long, complex sentence that describes in detail the massacre in which his grandfather was involved. As such, Foer refuses to provide a definitive stance on Holocaust representability.

The film, by contrast, focuses solely on Alex's narrative, and as a result, presents a less equivocal set of ethics. This is especially apparent in the excision of the moral ambiguities surrounding Alex's grandfather and his actions during the war, as I will discuss later. A comparison of the two, therefore, is fruitful in understanding the ways in which the types of media influence the ethics portrayed. The majority of the following, however, will focus on the relationship between a subversion of conventional Holocaust representation and an explication of the third generation experience. Though I will examine the use of humour throughout as the centrepoint of my argument, I will do so in relation to the ethical guidelines established above: fidelity to historical fact; insistence on the uniqueness of the Holocaust; and preservation of a strict morality.

\subsection{Fidelity to Historical Fact: An Imagined History}

The issue of historicity is clearly raised from the very start of both the novel and film versions of Everything is Illuminated. Most obviously, this is achieved through the presence of a character who shares a name with the author, and, as previously mentioned, embarks upon a journey that it is widely known Foer himself made, thus establishing a claim to authenticity. In the novel, Foer takes further measures to consolidate this, such as by including a note in one of Alex's letters advising him that he 'will not require that [his] name is on the cover. You [Jonathan] may pretend that it is only yours' (Foer 2003, p. 104). Indeed, on the cover of the book the reader holds in their hands, the name 
Alexander Perchov does not appear, hence increasing the sense that it is the fruit of the two men's joint creative project. In a way, the book itself is presented as the end product of its own narrative. Of course, however, the novel is in reality a work of fiction. The blurring of the fiction/nonfiction boundary hence complicates the process of separating fact from imagination, a concern relevant to many members of the third generation: in the absence of clear facts, a sense of the past must be built in a large part upon conjecture. For this reason, though critics such as Aliki Varvogli have described Everything is Illuminated as 'semi-autobiographical' (Varvogli 2012, p. 82), it is perhaps better characterised as autofictional. A term usually associated with French literature, Hywel Dix defines autofiction as

a project of self-exploration and self-experimentation on the part of the author. This in turn is partly because many works of autofiction have been written in the aftermath of some kind of traumatic experience-real or imagined-so that the process of writing in response to trauma can be seen as a means of situating the self in a new context when other relational constructs have been removed or jeopardized. (Dix 2018, p. 4)

Similarly, in the context of the third generation, the self must be situated in a social world where the Holocaust is omnipresent as an overwhelming absence; an oxymoron which entails a different relationship with historical fact and chronology.

Historicity is not only problematised in the contemporary parts of the narrative of Everything is Illuminated, however, but also in its depictions of the events leading up to the destruction of Trachimbrod during the Holocaust. This has proved a point of considerable contention for one of Foer's main detractors, Ivan Katchanovski. Excoriating Foer for 'distort[ing] history', Katchanovski writes that ' $[w]$ hen Foer, who uses his real name and names of real places in Ukraine in his book, went to Ukraine to locate a rescuer of his grandfather, he found nothing. So he wrote the novel based on his imagination' (Katchanovski 2004, n. p.). Yet, this is exactly the point. The colourful, and oftentimes playfully humorous, history of Trachimbrod imagined by Foer fills in the absence of the history created by the silencing effects of the Holocaust, conflating, as Anna Hunter argues, the impossibility of magic with the impossibility of memory (Hunter 2013, p. 66). In this sense, Philippe Codde notes, the narrative approximates mythology, explaining that 'in the absence of historical "facts", myth becomes a valid alternative to illuminate one's origins' (Codde 2009, p. 65). Moreover, the vibrant depictions of shtetl life-especially the annual Trachimday parade and festival—verge on Mikhail Bakhtin's concept of the carnivalesque, which has as one of its aims 'a shift of authorities and truths, a shift of world orders' (Bakhtin 1984, p. 127). In this way, it becomes an act of rebellion. Within the context of Foer's family history, this rebellion is aimed precisely at the Nazi powers that annihilated his family history, and created the very absence that this narrative seeks to fill. As such, the humorous history of Trachimbrod can be regarded as an act of resilience and a refusal to ennoble suffering. As Francisco Collado-Rodríguez elucidates, the narrative serves 'to not only overcome a lack of an [sic] historical referent, but also to cope emotionally with the Nazis' massacre of Jews' (Collado-Rodríguez 2008, p. 57). It is the creation of laughter that refuses to suffer not under the direct influence of the Nazis, but arises from the absurdity of the black hole that is the legacy of the Holocaust, and the trauma it entails. This act, Tracy Floreani notes, exemplifies Foer's refusal 'to let the entire narrative of his family be reduced to just a Holocaust story' (Floreani 2011, p. 147). It functions as a denial of the Nazis' continued dominion over his and his family's lives.

In addition to creatively filling a historical absence, the playfulness of the history of Trachimbrod also allows Foer to underline and analogize different aspects of his experience as a third generation survivor. Codde argues that the first chapter of Jonathan's narrative, in which a carriage plunges into the Brod and many random items float to the surface, acts as 'a beautiful metaphor for Holocaust historiography'. He explains that 'after the crisis, the scattered evidence, the fragmented material elements, slowly float to the river's surface, which people desperately try to collect and make sense of via a host of narrative employments' (Codde 2009, p. 74 n3). The legacy of the Holocaust is similarly analogized in the white string that is used as part of the decoration for the Trachimday festival. The thread represents the comically absurd string one inhabitant of the shtetl, Sofiowka, tied 
around his index finger to remember something terribly important, and fearing he would forget the index finger, he tied a string around his pinky, and then one from waist to neck, and fearing he would forget this one, he tied a string from ear to tooth to scrotum to heel, and used his body to remember his body, but in the end could remember only the string. (Foer 2003, p. 15)

The inability to remember a specific detail, substituted for remembering remembrance itself, echoes the lack of information available on the Holocaust that may be accessible to third generation survivors and the prolific use of the maxim 'never forget', despite the phrase often being unreflective and devoid of any real substance. A solution to this problem is also suggested metaphorically, through the fable-like story of the Wisps of Ardisht, who realise that they are running out of matches to light their cigarettes. They believe that soon they will no longer be able to smoke, until a child recognises that so long as at least one cigarette is lit at all times, they can light the others from that (Foer 2003, pp. 136-37). This translates well into the crisis of the loss of Holocaust survivors who are able to bear testimony and the mechanisms for doing so, and a call to subsequent generations to keep the memory alight, as it were. Although these are just a few of many examples, they illustrate several aspects of the third generation's experience that may be less affective or relatable when presented directly, combined with the use of colourful and gently humorous characters that reject a glorification of suffering.

\subsection{Insistence on the Uniqueness of the Holocaust: An Ethnic Comedy}

Whilst Everything is Illuminated focuses strongly on the legacies of the Holocaust, it is notable that the Holocaust itself-despite even being the motivating force behind the journey to Ukraine-comprises very little of the finished narrative. In fact, the Holocaust is never actually verbalised in (Jewish) Jonathan's account, and is only registered directly in (gentile) Alex's chapters. The sense of incongruity is heightened by the fact that the parts narrated by Alex are especially humorous, hence rendering the harrowing descriptions of Nazi brutality additionally jarring. Consequently, notions of the Jewish uniqueness of the Holocaust are already destabilised.

Much of the humour in the novel is derived from the particular narrative style of Alex's chapters, which are written in a thesaurus-inflected English riddled with misremembered idioms. For example, he describes how he 'performed recklessly well in my second year of English at university. This is a very majestic thing I did because my instructor was having shit between his brains' (Foer 2003, p. 2). In fact, as Varvogli writes, 'it is at times hard to decide if we should be laughing at or with our Ukrainian narrator' (Varvogli 2012, p. 88). Mita Banerjee takes this further, suggesting that '[i]t seems regrettable [...] that Foer's American humor should capitalize on an Eastern European character's inadeptness at getting things "right["]' (Banerjee 2009, p. 150 n4). However, as the narrative progresses, the opposite is true. Jonathan is markedly out of place both linguistically and culturally, subverting the expected relationship between erudition and education. The comedy, therefore, heavily relies once again upon incongruity. In one instance, Jonathan offers a packet of Marlboro cigarettes as a tip to a Ukrainian man who gave them directions. This causes a great deal of confusion amongst his Ukrainian guides, both with regards to the concept of a tip and the meaning of the cigarettes themselves. Furthermore, his explanation that 'I read in my guidebook that it's hard to get Marlboro cigarettes here' seems outdated at best (likely harking back to the Soviet era, in which American products were often impossible to obtain legitimately), implying that Jonathan is extremely ignorant of contemporary Ukrainian culture (Foer 2003, p. 109). Similarly, in the film, Jonathan's extensive knowledge of Jewish history in Eastern Europe is juxtaposed with his lack of knowledge of the years following the war. He seems bewildered by the corroded radiation signs and derelict buildings the car passes, to which Alex simply responds with the word 'Soviets' (Schreiber 2005). Thus, by exposing the limitations of Jonathan's perspective on the historical and contemporary context of Eastern Europe, Schreiber's adaptation subtly augments the sense of a second painful traumatic legacy in Ukraine-and one that is, in several ways, comparable to the Holocaust. Hence, the uniqueness of the Holocaust as an event-as opposed to a specifically Jewish event-is also questioned. 
However, the film ultimately affirms the uniqueness of the Holocaust more than it disputes it. Primarily, this is achieved through providing Alex's grandfather with the identity of a Jewish victim, who survived execution at the hands of Nazi soldiers. Not only is this in direct contrast to the plot of the book, but it also reinserts a Jewish presence which exists largely as an absence in the text. In this way, the Jewish victims of the Holocaust are recentralised within the narrative, and the Holocaust is consolidated as its principal trauma. Conversely, in the novel, it is revealed that Alex's grandfather acted as a perpetrator during the Holocaust, having pointed out his Jewish friend Herschel to the Nazis in order to save his own and his family's lives. The long, rambling passage in which this scene is described reflects its traumatic impact on both Alex and his grandfather, in which punctuation, and even the spacing between words, disintegrates. In the words of Axel Stähler and Annette Kern-Stähler, 'language becomes fused and confused as do the identities of perpetrator and victim and witness and interpreter' (Stähler and Kern-Stähler 2009, p. 175). Foer hence advances the question of non-Jewish victimhood and trauma arising from the Holocaust, summarised in Alex's grandfather's claim that '[j] ust because I was not a Jew, it does not mean that it did not happen to me' (Foer 2003, p. 246); an assertion that will be examined in more detail in the following section.

\subsection{Preservation of a Strict Morality: The Banality of Evil}

Where the majority of Alex's sections of the book (and the first half of the film) are marked by their humour, it is at the point of the explication of the Holocaust that the humour implodes. While this intensifies the effects of the incongruity, it also demarcates a clear boundary between laughter as a refusal to suffer or to defamiliarise expected norms, and laughter aimed at suffering itself. Consequently, neither narrative makes light of the tragedy of the Holocaust. Whether Alex's grandfather is to be considered a victim or a perpetrator, the horrors he witnesses and/or participates in are never trivialised. In terms of the novel, the acknowledgement of his trauma complicates widely held beliefs regarding clear dichotomies between victims and perpetrators; pure good and absolute evil. That is not to say, of course, that there is no differentiation between the categories of victims and perpetrators, even with regards to trauma; but rather that the degrees of slippage present between the two must be recognised. It is symptomatic of a third generation movement towards a more balanced understanding of the Holocaust, which recognises the problematic nature of strict moral categories, and, correlatively, the ambiguous ethicality of many persons involved, such as Jewish perpetrators. Indeed, far from committing a 'fundamental wrong', as Banerjee would have it, Alex's grandfather was unable to make a choice that was purely morally good (Banerjee 2009, p. 166). As Franklin astutely submits, '[h]ow can we who "live after"-who experienced no persecution or privation-judge the actions of those who lived during?' (Franklin 2010, p. 8). Equally, through his depiction of Alex's grandfather's terror and the appalling dilemma with which he was faced, Foer discourages clear-cut categorisations of good and evil, both in character and in actions.

Certainly, to unequivocally condemn Alex's grandfather seems significantly problematic. Similarly, to insist upon innocence as a requisite for the categories of 'victim' or 'traumatised' constitutes a reductive denial of different experiences, including the existence of perpetrator trauma. Such ethical reductionism has been prolific, encompassing both personal and national spheres. As Bernhard Giesen notes, the Holocaust has had a major impact on German national identity, and especially in the years following the war the German people have been denied a sense of traumatic history-thus excising the traumatic impact of catastrophes such as the Allied firebombing of Dresden, which took around 25,000 lives, and left hundreds of thousands more injured-due to their characterisation as perpetrators against the Jewish people (Giesen 2004, p. 115). A parallel scenario is considered within Everything is Illuminated, regarding the antisemitism of pre- (and post-) war Ukraine, as the trauma is displaced from cultural generalisations onto a more individualised basis. In this, not only is the personal Holocaust-based trauma of a gentile examined (Alex's grandfather), but so too are the circumstances of his complicity in the massacre. By writing the account of the atrocity through the first person perspective-albeit mediated through Alex's translation, which, although still retaining 
its idiosyncratic English, is no longer deployed for comedic effect, instead suggesting the limits of language in describing a trauma-Foer appeals to a humanistic empathy for those whom history has branded the antagonists. This humanisation is reminiscent of Hannah Arendt's concept of the banality of evil; the realisation that 'many [perpetrators of the Holocaust] were neither perverted nor sadistic, that they were, and still are, terribly and terrifyingly normal' (Arendt 1965, p. 276). Foer's representation of the Holocaust, therefore, defies simplistic moralisation, and accordingly refuses to bifurcate those affected into heroes and villains. They are, to use Arendt's term, 'normal'; or in the words of Alex's grandfather, 'good [people] who ha[ve] lived in a bad time' (Foer 2003, p. 227). Hence, the Holocaust is treated less as having been effectuated solely through the unchangeably bad character of its perpetrators, and more as a reciprocal influence in and of itself on people's actions.

However, much of this nuance is excluded from Schreiber's film adaptation, as the Jewish identity of Alex's grandfather allows him to fit the conventional role of the innocent victim. In this, not only does the film reaffirm the uniqueness of the Holocaust, but also portrays a very typical Holocaust morality. One possible explanation for this decision arises from the change in media type. Whilst Foer's novel has been hugely popular with both the public and academic circles, film as a medium-and especially a film created by a division of major film studio Warner Bros.--has long been considered a more popular genre, and (rather unfairly) a less intellectual one. Its accessibility and immediacy therefore place it more firmly within the category of mass media, which, as Giesen observes, contains some very specific imperatives:

In contrast to scholarly research, reconstructions of the past in the mass media have to abstain from referring to abstract figures and arguments; instead they must narrate a story about good and bad people. They have to create suspense and emotions and offer clear-cut anchors for identification. (Giesen 2004, pp. 141-42)

In terms of identification, it is undoubtedly less troubling to identify with Alex's grandfather as a victim, an action which does not challenge the viewer's perceptions of moral good or their own ethicality. In this, it functions effectively in terms of Alison Landsberg's concept of 'prosthetic memory', in which mass media allows individuals to identify with and engage with histories that are not their own (Landsberg 2004). This identification-which, Landsberg argues, is facilitated more so in the medium of film than in literature, due to the film's unilateral control over the images and the pacing of their exhibition, and therefore allowing for a stronger mimetic response to the characters depicted on screen (Landsberg 2009) - brings a strong emotive quality to the horrors faced by Jewish people during the Holocaust. The lack of humour during these scenes reinforces this purpose, ensuring that the tragedy is portrayed seriously, uncomplicated by a jocularity that might invite a viewer to laugh at or trivialise the situation. Ultimately, however, although the film persuasively highlights many of the impacts of the Holocaust on its victims and subsequent generations, it does not call into question our understanding of this history itself. In this way, it upholds a much more conservative ethics of Holocaust representation.

\section{Concluding Remarks}

In her book entitled A Thousand Darknesses, Franklin invites us to reexamine the common translation of Adorno's dictum, used at the start of this article:

Nach Auschwitz ein Gedicht zu schreiben, ist barbarisch. Notice that he wrote 'ein Gedicht' - not 'poems' or 'poetry' but 'a poem.' Sometimes I imagine that he might, perhaps even subconsciously, have meant the statement literally. It would be horrific to write only one poem after Auschwitz. But to write a hundred poems, a thousand poems, a million-that might be better, because it would take an infinite number of works of literature to represent the vast multiplicity of voices and experiences that constitute the Holocaust. (Franklin 2010, p. 19)

Perhaps this translation is more apt. The Holocaust—-that omnipresent absence-continues to haunt the present day long after the liberation of the camps, and, what is more, constantly precipitates new 
experiences and relations. In this way, it must be considered less a finalised, past event, and more a dynamic history in motion; a process of narrative construction and creation that may never be complete. Because of this, it is important not only to engage with direct, documentary portrayals and memoirs, but to also to receive new forms of creative inquiry, from imaginative portrayals of the events of the twentieth century to explorations of their legacy in popular culture, including the humorous forms that are prevalent amongst the third generation. After all, though it would be wrong to suggest that anyone has experienced - and experiences-the Holocaust in the same way or degree that a survivor might, it would be equally wrong to suggest that they do not experience it at all. The experience of the Holocaust is unprecedentedly multifaceted, and is certainly not linked to one particular period of time.

Most importantly, however, it is through works like these that the memory of the Holocaust is kept alive. A central concern for many members of the third generation, the memorialisation of the Holocaust has never been seriously doubted: it is imperative that we remember, the issue has always been how. And indeed, while the ethical guidelines I have placed under scrutiny here have existed in order to do so in the most sensitive manner possible, they are ultimately insufficient to cater for the multifarious nature of Holocaust experience, past and present. As Banerjee writes, ' $[\mathrm{m}]$ emory is kept alive, not through the invocation of duty, but through the rousing of curiosity' (Banerjee 2009, p. 148). Indeed, Everything is Illuminated fits this purpose well. The popularity of both the book and the film have placed the narrative firmly within the public consciousness, bolstered by the playfulness of its imaginative and humorous narrative. Its defiance of expectations regarding fiction about the Holocaust, in this way, arouse the curiosity necessary for engagement with its history, and thus it upholds the third generation ethical concern to remember. Finally, Foer suggests, within this call is one further responsibility: the element of choice. Just as Alex's grandfather was presented with a choice, so too must the writer of Holocaust fiction choose how to present the tragedy. If history was not, and is not, fixed, and its actors bound not by fate but by agency; then neither must representation.

Funding: This research is part of Sarah Coakley's Ph.D. project which is funded by the University of Dundee.

Acknowledgments: The author is grateful to Aliki Varvogli and Golnar Nabizadeh, for reading and providing insights on an earlier version of this manuscript.

Conflicts of Interest: The author declares no conflict of interest. The founding sponsor had no role in the design of the study; in the collection, analyses, or interpretation of data; in the writing of the manuscript, and in the decision to publish the results.

\section{References}

Aarons, Victoria, and Alan L. Berger. 2017. Third Generation Holocaust Representation: Trauma, History, and Memory. Evanston: Northwestern University Press.

Adorno, Theodor W. 1981. Prisms. Translated by Samuel, and Shierry Weber. Cambridge: MIT Press.

Agaibi, Christine E., and John P. Wilson. 2005. Trauma, PTSD, and Resilience: A Review of the Literature. Trauma, Violence, \& Abuse 6: 195-216.

Arendt, Hannah. 1965. Eichmann in Jerusalem: A Report on the Banality of Evil, rev. ed. Harmondsworth: Penguin.

Bakhtin, Mikhail. 1984. Problems of Dostoevsky's Poetics. Edited and Translated by Caryl Emerson. Manchester: Manchester University Press.

Banerjee, Mita. 2009. Roots Trips and Virtual Ethnicity: Jonathan Safran Foer's Everything is Illuminated. In Transnational American Memories. Edited by Udo J. Hebel. Berlin: De Gruyter, pp. 145-69.

Benigni, Robert. 1998. Life Is Beautiful. DVD. Rome: Melampo Cinematografica.

Braun, Robert. 1994. The Holocaust and Problems of Historical Representation. History and Theory 33: $172-97$. [CrossRef]

Chaitin, Julia. 2002. Issues and interpersonal values among three generations in families of Holocaust survivors. Journal of Social and Personal Relationships 19: 379-402. [CrossRef]

Codde, Philippe. 2009. Transmitted Holocaust Trauma: A Matter of Myth and Fairy Tales? European Judaism 42: 62-75. [CrossRef] 
Cohen, Sarah Blacher. 1987. Introduction: The Varieties of Jewish Humor. In Jewish Wry: Essays on Jewish Humor. Edited by Sarah Blacher Cohen. Detroit: Wayne State University Press, pp. 1-15.

Collado-Rodríguez, Francisco. 2008. Ethics in the Second Degree: Trauma and Dual Narratives in Jonathan Safran Foer's Everything Is Illuminated. Journal of Modern Literature 32: 54-68. [CrossRef]

Costa, Dora L., Noelle Yetter, and Heather DeSomer. 2018. Intergenerational transmission of paternal trauma among US Civil War ex-POWs. Proceedings of the National Academy of Science of the United States of America 115: 11215-20. [CrossRef]

Critchley, Simon. 2002. Did you hear the One about the Philosopher Writing a Book on Humour? Think 1: 103-12. [CrossRef]

Dix, Hywel. 2018. Introduction: Autofiction in English: The Story so Far. In Autofiction in English. Edited by Hywel Dix. Cham: Palgrave Macmillan, pp. 1-23.

Eckardt, A. Roy. 1992. Divine Incongruity: Comedy and Tragedy in a Post-Holocaust World. Theology Today 48 : 399-412. [CrossRef]

Floreani, Tracy. 2011. Metafictional Witnessing in Jonathan Safran Foer's Everything is Illuminated. In Unfinalized Moments: Essays in the Development of a Contemporary Jewish Narrative. Edited by Derek Parker Royal. West Lafayette: Purdue University Press, pp. 139-49.

Foer, Jonathan Safran. 2003. Everything Is Illuminated. London: Penguin.

Franklin, Ruth. 2010. A Thousand Darknesses: Lies and Truth in Holocaust Fiction. Oxford: Oxford University Press.

Freud, Sigmund. 1960. Jokes and their Relation to the Unconscious. In The Standard Edition of the Complete Psychological Words of Sigmund Freud. Edited by James Strachey. Translated by James Strachey, and Anna Freud. London: Hogarth Press, vol. 8, pp. 9-236. First published 1905.

Freud, Sigmund. 1961. Humour. In The Standard Edition of the Complete Psychological Works of Sigmund Freud. Edited by James Strachey. Translated by James Strachey, and Anna Freud. London: Hogarth Press, vol. 21, pp. 159-66. First published 1927.

Fromm, M. Gerard. 2012. Introduction. In Lost in Transmission: Studies of Trauma Across Generations. Edited by M. Gerard Fromm. London: Routledge, pp. xv-xxi.

Giesen, Bernhard. 2004. The Trauma of Perpetrators: The Holocaust as the Traumatic Reference of German National Identity. In Cultural Trauma and Collective Identity. Edited by Jeffrey C. Alexander, Ron Eyerman, Bernard Giesen, Neil J. Smelser and Piotr Sztompka. Berkeley: University of California Press, pp. 112-54.

Ginsparg, Sylvia Levine. 2003. Humor and the Holocaust: Turning Comedians into Victims to End the Millennium. Psychoanalytic Psychology 20: 710-16. [CrossRef]

Gray, Sarah A. O., Christopher W. Jones, Katherine P. Theall, Erin Glackin, and Stacy S. Drury. 2017. Thinking Across Generations: Unique Contributions of Maternal Early Life and Prenatal Stress to Infant Physiology. Journal of the American Academy of Child E Adolescent Psychiatry 56: 922-29.

Hirsch, Marianne. 2008. The Generation of Postmemory. Poetics Today 29: 103-28. [CrossRef]

Hunter, Anna. 2013. Tales from Over There: The Uses and Meanings of Fairy-Tales in Contemporary Holocaust Narrative. Modernism/modernity 20: 59-75. [CrossRef]

Katchanovski, Ivan. 2004. NOT Everything is Illuminated. Prague Post. October $7 . \quad$ Available online: https://web.archive.org/web/20140328011839/http:/www.praguepost.cz/archivescontent/40032-noteverything-is-illuminated.html (accessed on 20 July 2019).

Landsberg, Alison. 2004. Prosthetic Memory: The Transformation of American Remembrance in the Age of Mass Culture. New York: Columbia University Press.

Landsberg, Alison. 2009. Memory, Empathy, and the Politics of Identification. International Journal of Politics, Culture, and Society 22: 221-29. [CrossRef]

Lang, Berel. 2000. Holocaust Representation: Art Within the Limits of History and Ethics. Baltimore: Johns Hopkins University Press.

Lanzmann, Claude. 1995. The Obscenity of Understanding: An Evening with Claude Lanzmann. In Trauma: Explorations in Memory. Edited by Cathy Caruth. Baltimore: Johns Hopkins University Press, pp. 200-20.

Lanzoni, Remi. 2000. Life is Beautiful: When Humor Challenges History. Forum Italicum 34: 121-35. [CrossRef]

Lehrner, Amy, and Rachel Yehuda. 2018. Cultural trauma and epigenetic inheritance. Development and Psychopathology 30: 1763-77. [CrossRef]

Lev-Wiesel, Rachel. 2007. Intergenerational Transmission of Trauma across Three Generations: A Preliminary Study. Qualitative Social Work 6: 75-94. [CrossRef] 
Lipman, Steve. 1991. Laughter in Hell: The Use of Humor during the Holocaust. Northvale: Jason Aronson.

Lyotard, Jean-François. 1997. Heidegger and "the Jews". Translated by Andreas Michel, and Mark Roberts. Minneapolis: University of Minnesota Press. First published 1988.

Muller, Christine. 2017. September 11, 2001 as a Cultural Trauma: A Case Study through Popular Culture. Cham: Palgrave Macmillan.

Nugent, Nicole R., Ananda B. Amstadter, and Karestan C. Koenen. 2008. Genetics of Post-Traumatic Stress Disorder: Informing Clinical Conceptualizations and Promoting Future Research. American Journal of Medical Genetics Part C (Seminars in Medical Genetics) 148: 127-32. [CrossRef]

Ostrower, Chaya. 2015. Humor as a Defense Mechanism during the Holocaust. Interpretation: A Journal of Bible and Theology 69: 183-95. [CrossRef]

Ramo-Fernández, Laura, Anna Schneider, Sarah Wilker, and Iris-Tatjana Kolassa. 2015. Epigenetic Alterations Associated with War Trauma and Childhood Maltreatment. Behavioral Sciences and the Law 33: 701-21. [CrossRef]

Reisz, Matthew J. 2002. Everything is Illuminated by Jonathan Safran Foer. Independent. June 21. Available online: https://www.independent.co.uk/arts-entertainment/books/reviews/everything-is-illuminated-byjonathan-safran-foer-181082.html (accessed on 20 July 2019).

Royal, Derek Parker. 2011. Unfinalized Moments: Essays in the Development of a Contemporary Jewish Narrative. Edited by Derek Parker Royal. West Lafayette: Purdue University Press, pp. 1-13.

Samuels, David. 2014. Do Jews Carry Trauma in Our Genes? A Conversation with Rachel Yehuda. Tablet. December 11. Available online: https://www.tabletmag.com/jewish-arts-and-culture/books/187555/traumagenes-q-a-rachel-yehuda. (accessed on 5 December 2018).

Scharf, Miri. 2007. Long-term effects of trauma: Psychosocial functioning of the second and third generation of Holocaust survivors. Development and Psychopathology 19: 603-22. [CrossRef]

Scharf, Miri, and Ofra Mayseless. 2011. Disorganizing Experiences in Second- and Third-Generation Holocaust Survivors. Qualitative Health Research 21: 1539-53. [CrossRef]

Schreiber, Liev. 2005. Everything Is Illuminated. DVD. Burbank: Warner Independent Pictures.

Sliter, Michael, Aron Kale, and Zhenyu Yuan. 2014. Is humor the best medicine? The buffering effect of coping humor on traumatic stressors in firefighters. Journal of Organizational Behavior 35: 257-72. [CrossRef]

Stähler, Axel, and Annette Kern-Stähler. 2009. The Translation of Testimony and the Transmission of Trauma: Jonathan Safran Foer's Everything is Illuminated and Liev Schreiber's Film Adaptation. In Voices and Silence in the Contemporary English Novel. Edited by Vanessa Guignery. Newcastle Upon Tyne: Cambridge Scholars Publishing, pp. 160-84.

Varvogli, Aliki. 2012. Travel and Dislocation in Contemporary American Fiction. New York: Routledge.

Wiesel, Elie. 1989. Art and the Holocaust: Trivializing Memory. New York Times. June 11. Available online: https://www.nytimes.com/1989/06/11/movies/art-and-the-holocaust-trivializing-memory.html (accessed on 10 July 2019).

Wilker, Sarah, and Iris-Tatjana Kolassa. 2012. Genetic Influences on Posttraumatic Stress Disorder (PTSD): Inspirations from a Memory-Centered Approach. Psychiatria Danubina 24: 278-79. [PubMed]

Yehuda, Rachel, and Linda M. Bierer. 2009. The Relevance of Epigenetics to PTSD: Implications for the DSM-V. Journal of Traumatic Studies 22: 427-34. [CrossRef] [PubMed]

Yehuda, Rachel, Sarah L. Halligan, and Linda M. Bierer. 2002. Cortisol levels in adult offspring of Holocaust survivors: relation to PTSD symptom severity in the parent and child. Psychoneuroendocrinology 27: 171-80. [CrossRef]

Yehuda, Rachel, Amanda Bell, Linda M. Bierer, and James Schmeidler. 2008. Maternal, not paternal, PTSD is related to increased risk for PTSD in offspring of Holocaust survivors. Journal of Psychiatric Research 42: 1104-11. [CrossRef]

Zandberg, Eyal. 2015. 'Ketchup Is the Auschwitz of Tomatoes': Humor and the Collective Memory of Traumatic Event. Communication, Culture E Critique 8: 108-23.

(C) 2019 by the author. Licensee MDPI, Basel, Switzerland. This article is an open access article distributed under the terms and conditions of the Creative Commons Attribution (CC BY) license (http://creativecommons.org/licenses/by/4.0/). 